\title{
Photocatalyzed Degradation of a Pesticide Derivative Glyphosate in Aqueous Suspensions of Titanium Dioxide
}

\author{
Mohammad Muneer ${ }^{1,2}$ and Colin Boxall ${ }^{1}$ \\ ${ }^{1}$ Centre for Material Science, University of Central Lancashire, Preston PR1 2HE, UK \\ ${ }^{2}$ Department of Chemistry, Aligarh Muslim University, Aligarh-202002, India
}

Correspondence should be addressed to Colin Boxall, cboxall@uclan.ac.uk

Received 24 July 2007; Revised 30 November 2007; Accepted 17 March 2008

Recommended by Russell Howe

The photocatalytic degradation of a herbicide derivative, glyphosate [(N-phosphonomethyl) glycine] has been investigated in aqueous suspensions of titanium dioxide at different $\mathrm{pH}$ values. This compound was found to degrade more efficiently under alkaline $\mathrm{pH}$, where no adsorption takes place on the surface of the catalyst in the dark. The main degradation route involves the cleavage of the $\mathrm{P}-\mathrm{C}$ bond giving rise to sarcosine and glycine as the intermediate products formed during the photooxidation process.

Copyright ( $) 2008$ M. Muneer and C. Boxall. This is an open access article distributed under the Creative Commons Attribution License, which permits unrestricted use, distribution, and reproduction in any medium, provided the original work is properly cited.

\section{INTRODUCTION}

A wide variety of organic pollutants especially pesticides are introduced into the water system from various sources such as industrial effluents, agricultural runoff, and chemical spills $[1,2]$. Their toxicity, stability to natural decomposition, and persistence in the environment have been the cause of much concern to the societies and regulatory authorities around the world $[3,4]$.

The control of organic pollutants in water is an important measure in environmental protection. Among many processes proposed and/or being developed for the destruction of the organic contaminants, biodegradation has received the greatest attention. However, many organic chemicals, especially those that are toxic or refractory, are not amendable to microbial degradation [5]. Recently, considerable attention has been focused on the use of semiconductor photocatalysis as a means to oxidise toxic organic chemicals [6-18]. The mechanism constituting heterogeneous photocatalytic oxidation processes has been discussed extensively in the literature (see, inter alia, $[19,20]$ ). In many of these studies, although the initial disappearance of the pollutant is rapid, a number of by products are formed which can also be potentially harmful to the environment.

The organophosphates exhibit considerable persistence in groundwaters and are highly hydrophilic. These com- pounds are the most prevalent pesticides and remain the choice of most farmers because of their effectiveness against large numbers of insect species. They are potent acetylcholinesterase inhibitors and are utilised to control chewing and sucking insects and spider mites on ornamental plants, citrus fruits, stone fruits, and other agriculture crops. For example, the pesticide derivative, glyphosate is a nonselective systemic herbicide that can control most annual and perennial plants [21]. It controls weeds by inhibiting the synthesis of aromatic amino acids necessary for protein formation in susceptible plants. Glyphosate is strongly adsorbed to soil particles, which prevents it from excessive leaching or from being taken up from the soil by nontarget plants [22-26]. It is degraded primarily by microbial metabolism, but strong adsorption to soil can inhibit microbial metabolism and slow degradation. The half-life of glyphosate ranges from several weeks to years, but averages are two months. In water, glyphosate is rapidly dissipated through adsorption to suspended and bottom sediments and has a half-life of 10-12 days [22-24, 27-29].

Although originally thought to be unaffected by sunlight [24], later studies found glyphosate to be susceptible to photodegradation. A half-life of 4 days in deionised water under UV light has been reported [30]. Recently, the photocatalytic degradation of glyphosate in the presence of $\mathrm{TiO}_{2}$ has been reported by Shifu and Yunzhang [31]. However, no effort has 


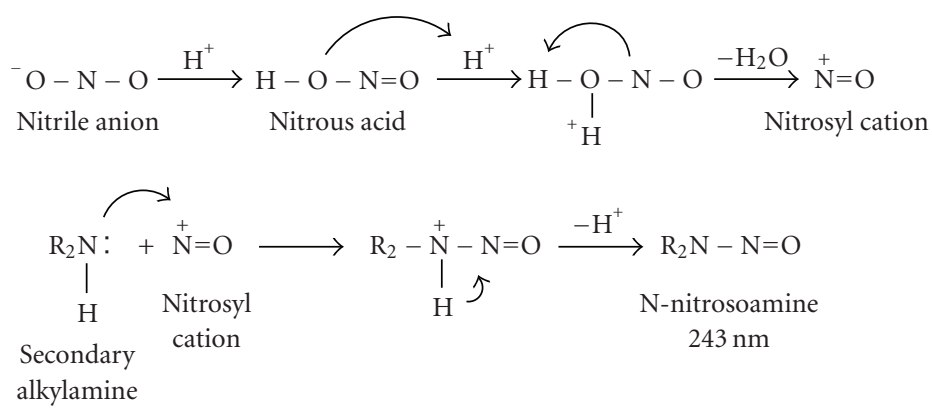

Scheme 1: Scheme showing the conversion of secondary amine to its $\mathrm{N}$-nitroso derivative on treatment with nitrous acid in the presence of acid.

been made to look into the degradation products. Therefore, we have studied the degradation of glyphosate in aqueous suspension of $\mathrm{TiO}_{2}$ with an aim to identify the products formed during the photooxidation process.<smiles>O=C(O)CNCP(=O)(O)O</smiles>

\section{EXPERIMENTAL METHODS}

\subsection{Reagent and chemicals}

Analytical grade glyphosate was obtained from Fluka and used without further purification. The water employed in this study was purified by a Millipore system. The photocatalyst titanium dioxide Degussa P25 was used in all the experiments reported here. Degussa P25 contains 75\% anatase and 25\% rutile with a specific BET surface area of $50 \mathrm{~m}^{2} \mathrm{~g}^{-1}$ and a primary particle size of $20 \mathrm{~nm}$ [32].

\subsection{Procedure}

A solution of glyphosate at the desired concentration was prepared in water. For the irradiation experiments, $80 \mathrm{~cm}^{3}$ of this desired solution was pipetted into a photochemical reactor. The $\mathrm{pH}$ of the reaction mixture was adjusted by adding a dilute aqueous solution of $\mathrm{HNO}_{3}$ or $\mathrm{NaOH}$. The photoreactor was comprised of a quartz glass reaction vessel equipped with a magnetic stirring bar, a water circulating jacket, and opening for gas supplies, placed within a bespoke circular photoirradiation system (photochemical reactors LTD Buckingham, UK) comprised of $12 \times 15$ watt Blacklight UVA lamps $\left(\lambda_{\max }=312 \mathrm{~nm}\right), 42 \mathrm{~cm}$ long.

The required amount of the particulate photocatalyst was added to the glyphosate solution, and the solution was stirred in the dark for 10 minutes to allow equilibration of the system so that the loss of compound from the solution phase due to to-particle adsorption can be taken into account. The zero time reading was obtained from blank solution kept in the dark but otherwise treated similarly to the irradiated solution. Photodegradation experiments were conducted by irradiating the sample solutions with $312 \mathrm{~nm}$ light, the irradiated solutions being continuously purged with air throughout each experiment. Samples $\left(5 \mathrm{~cm}^{3}\right)$ were collected before and at regular intervals during the irradiation. These were centrifuged before being subjected to analysis.

\subsection{Sample analysis}

Elucidation of the mechanism and kinetics of photocatalytically driven glyphosate degradation requires a means to follow the concentration of glyphosate as a function of time. Secondary amines such as glyphosate and sarcosine are most easily determined by spectroscopic analysis of their nitro derivative. All secondary alkyl or aryl amines yield $\mathrm{N}$ nitrosoamines with an absorbance at or about $\lambda=243 \mathrm{~nm}$. Scheme 1 shows the route by which secondary amines are transformed to the $\mathrm{N}$-nitroso compounds.

The procedure for both calibration measurements and the analysis of experimental samples, whether derived from dark adsorption experiments (vide infra) or photodegradation experiments, involves the shaking of centrifuged glyphosate adsorbed or irradiated solutions $\left(1 \mathrm{~cm}^{3}\right.$ of expt. sample or $1 \mathrm{~cm}^{3}$ of $1 \times 10^{-3} \mathrm{~mol} \mathrm{dm}^{-3}$ calibration solution) in the presence of water $\left(5 \mathrm{~cm}^{3}\right), \mathrm{H}_{2} \mathrm{SO}_{4}\left(1: 1,0.5 \mathrm{~cm}^{3}\right), \mathrm{KBr}$ $\left(25 \%, 0.1 \mathrm{~cm}^{3}\right)$, and $\mathrm{NaNO}_{2}\left(0.2 \mathrm{~N}, 0.5 \mathrm{~cm}^{3}\right)$ in a $25 \mathrm{~cm}^{3}$ red volumetric flask for 30 minutes followed by dilution with water to $25 \mathrm{~cm}^{3}$. Absorbance was measured at $243 \mathrm{~nm}$ versus blank reagent containing all above reagents except glyphosate.

The product analysis was carried out using HPLC (Perkin Elmer 410 Bio) fitted with a nitrile column (cyanopropyl $5 \mu \mathrm{m})$. The eluent consisted of pure water; the compounds were detected employing a UV-detector at $254 \mathrm{~nm}$.

\section{RESULTS AND DISCUSSION}

\subsection{Dark adsorption of Glyphosate onto $\mathrm{TiO}_{2}$}

The possible dark adsorption of glyphosate on the surface of the photocatalyst was investigated by stirring aqueous solutions of glyphosate $\left(1 \times 10^{-3} \mathrm{~mol} \mathrm{dm}^{-3}, 35 \mathrm{~cm}^{3}\right)$ at a range of $\mathrm{pH}$ in the absence of illumination for 4 hours at different catalyst loadings $\left(2-10 \mathrm{~g} \mathrm{dm}^{3}\right)$. Analysis of samples after centrifugation using the $\mathrm{N}$-nitroso method (vide supra) showed that greatest adsorption occurs at lower $\mathrm{pH}$ values and that the extent of adsorption decreases as $\mathrm{pH}$ increases, as can be seen in Figure 1. 
TABLE 1: Table showing different forms of glyphosate and the net charge on glyphosate and the surface of $\mathrm{TiO}_{2}$ as a function of pH.

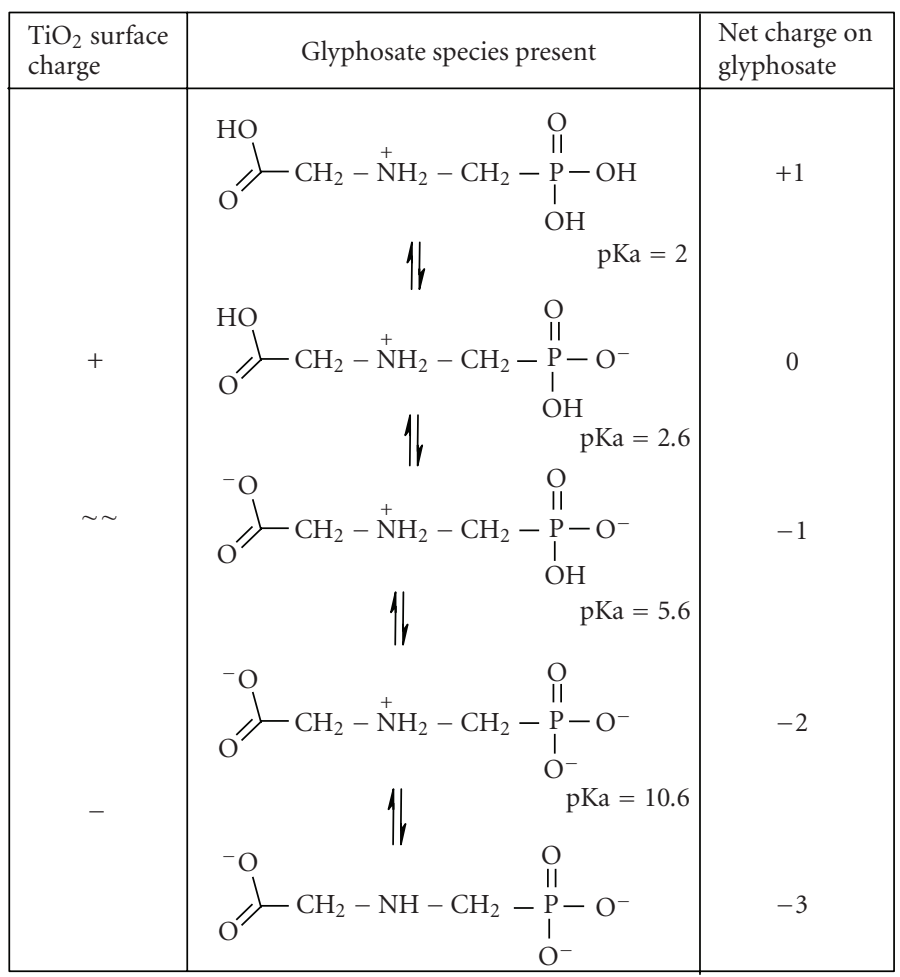

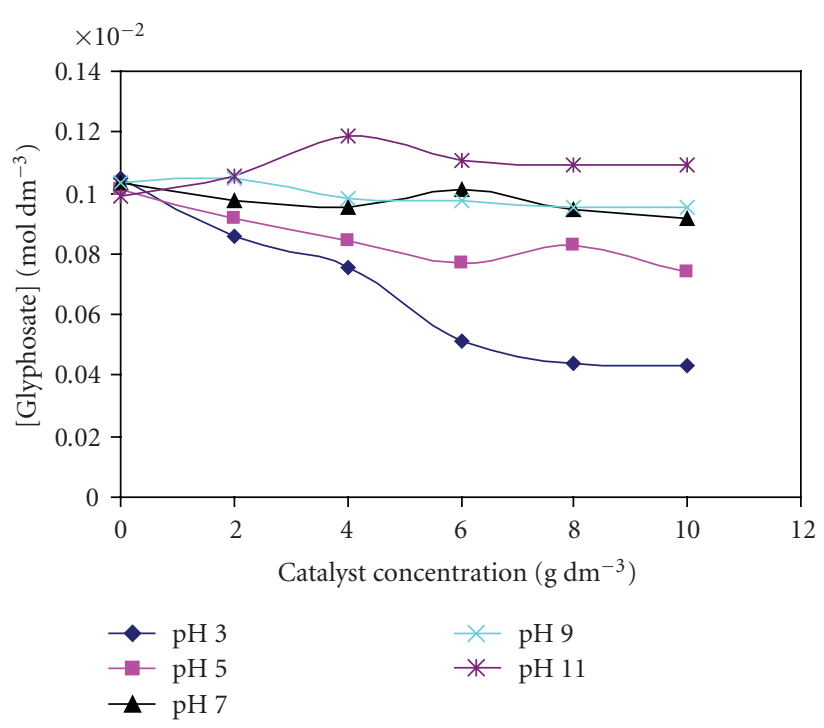

FIgURE 1: Glyphosate adsorption on the surface of Degussa P25 $\mathrm{TiO}_{2}$ photocatalyst in the dark at different $\mathrm{pH}$, assessed by measuring the concentration of free solution glyphosate as a function of solution loading of the catalyst.

This behaviour could be attributed to glyphosate containing three functional groups-phosphate, amino, and carboxylic - all of which can be protonated and deprotonated depending on individual functional group pKa values.

The point of zero charge (pzc) of $\mathrm{TiO}_{2}$ (Degussa P25) is widely reported as $\mathrm{pH} \sim 6.25$ [33]. With this in mind, Table 1 shows the ionic structure of glyphosate indicating the net charge on the molecule and $\mathrm{TiO}_{2}$ surface as different $\mathrm{pH}$ values.

At low $\mathrm{pH}$ values $(\sim \mathrm{pH} 3)$, the $\mathrm{TiO}_{2}$ surface will be positively charged, while the phosphate group of glyphosate will be negatively charged leading to the expectation that the compound will adsorb the surface of $\mathrm{TiO}_{2}$. In contrast, at higher $\mathrm{pH}$ values, the catalyst surface as well as the compound will be negatively charged, and hence adsorption in dark would not be expected, as evident from the experimental results shown in Figure 1. The Langmuir constants at $\mathrm{pH} 3$ (glyphosate uncharged, where phosphate is -1 and the $\mathrm{TiO}_{2}$ surface has a net positive charge) and $\mathrm{pH} 5$ (when glyphosate is -1 (phosphate and carboxlate are both -1 ) and $\mathrm{TiO}_{2}$ is slightly positive/near neutral) have been calculated as being 88610 and $1087 \mathrm{dm}^{3} \mathrm{~mol}^{-1}$, respectively. At $\mathrm{pH} 7$ (when glyphosate is -2 (phosphate -2 , carboxylate -1 ) and the $\mathrm{TiO}_{2}$ surface has a net negative charge), there is little evidence of any adsorption. Results at $\mathrm{pH} 9$ and $\mathrm{pH} 11$ are similar to those at $\mathrm{pH}$ 7. Therefore, the Langmuir adsorption pattern is congruent with that expected from columbic arguments. The magnitude of the adsorption coefficient at $\mathrm{pH} 3$ compared with that at $\mathrm{pH} 5$ suggests that the primary locus of adsorption is through phosphate group.

\subsection{Photocatalytic destruction of Glyphosate on $\mathrm{TiO}_{2}$-loss of Glyphosate}

Irradiation of an aqueous suspension of glyphosate $\left(80 \mathrm{~cm}^{3}\right.$, $1 \times 10^{-3} \mathrm{~mol} \mathrm{dm}^{3}$ ) in the presence of $\mathrm{TiO}_{2}$ (Degussa P25, 


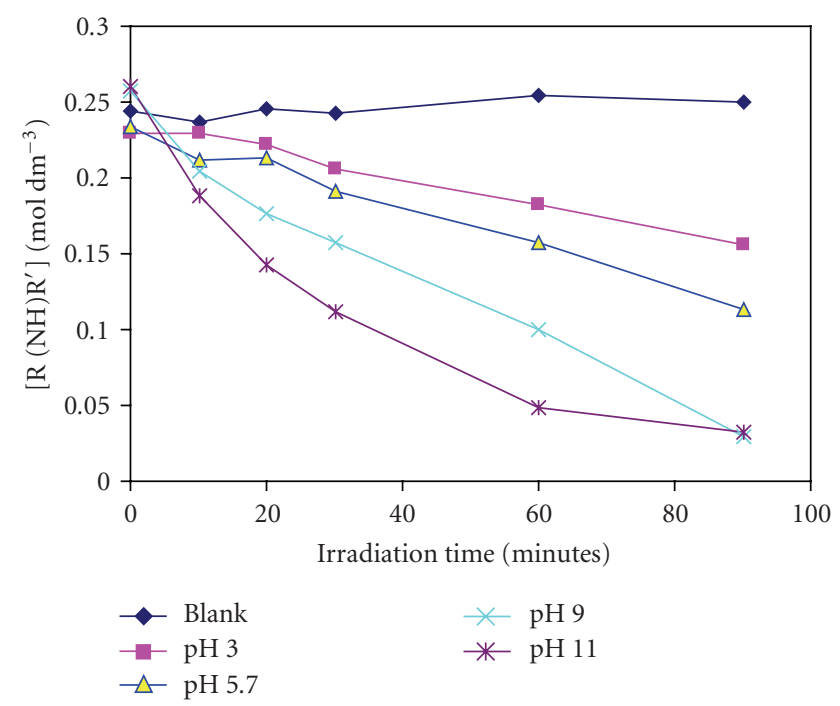

Figure 2: Photocatalytically induced loss of secondary amine functionality (measured using the N-nitroso method, see text) in glyphosate as a function of $\mathrm{pH}$.

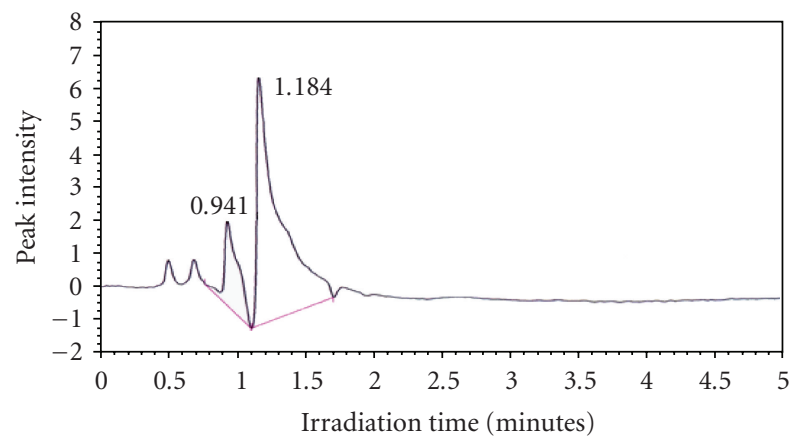

FIGURE 3: HPLC analysis of glyphosate in aqueous suspension of $\mathrm{TiO}_{2}$ in the dark (zero irradiation time).

$1 \mathrm{~g} \mathrm{dm}^{3}$ ) using $312 \mathrm{~nm}$ light in a tubular photochemical reactor with constant stirring and bubbling of air led to a decrease in glyphosate concentration as a function of time. The photodegradation was investigated at $\mathrm{pH}$ values $3,5.7$, 7,9 , and 11 . The decrease in secondary amine concentration (as determined by the $\mathrm{N}$-nitroso method, vide supra) as a function of irradiation time at different $\mathrm{pH}$ values is shown in Figure 2. The net loss and rate of loss of secondary amine was found to increase with the increase in $\mathrm{pH}$, the highest rate being observed at $\mathrm{pH} 11$. Further, for data recorded at $\mathrm{pH} 3$ and $\mathrm{pH}$ 5.7, there appears to be an induction period during which no loss of secondary amine is observed for a time immediately after the onset of illumination. We will return to this point below.

\subsection{Photocatalytic destruction of Glyphosate on $\mathrm{TiO}_{2}$-product analysis}

Figure 3 shows the HPLC trace of an aqueous suspension of glyphosate and $\mathrm{TiO}_{2}$ at zero time irradiation indicating a strong peak at retention time $R_{t}=1.184$ minutes and a medium peak at $R_{t}=0.941$ minute. Irradiation of the

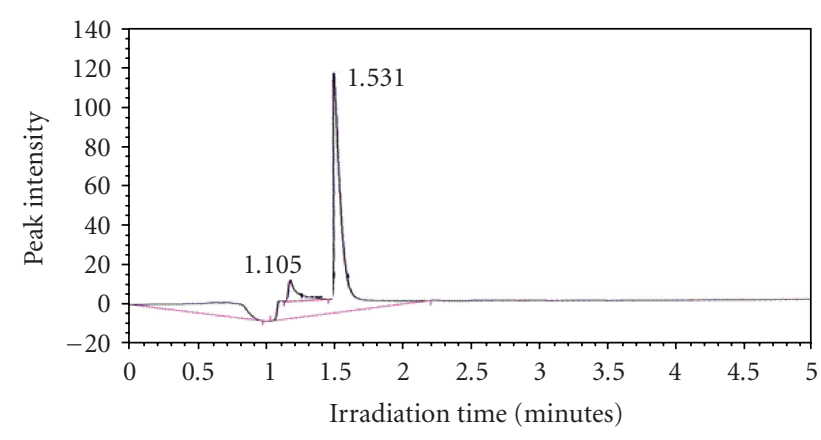

FIGURE 4: HPLC analysis of authentic sarcosine in aqueous solution.

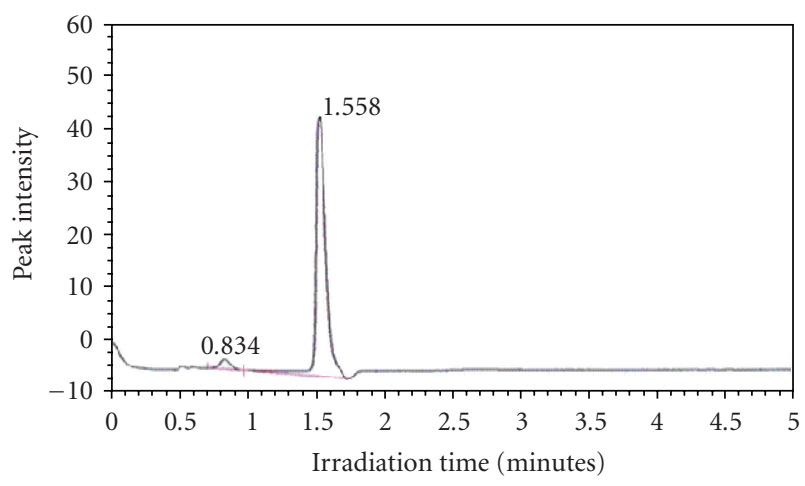

FIGURE 5: HPLC analysis of authentic glycine in aqueous solution.

solution for 90 minutes at $\mathrm{pH} 2$ led to the formation of a product which is indicated by appearance of a strong peak at $R_{t}=1.651$ minutes and a shoulder at $R_{t}=1.599$ minutes in addition to the unchanged starting material (see Table 2). Said product exhibited an HPLC retention time and peak shape typical of a carboxylic acid (determined through comparison with HPLC analysis of methanoic and ethanoic acids on same instrument, not shown). However, during this period, no concomitant loss of secondary amine was observed leading us to conclude that the $\mathrm{C}-\mathrm{P}$ bond had been broken in the formation of this product and that the product itself was most likely the amino acid sarcosine-N-methyl-2aminoethanoic acid. The HPLC trace of authentic sarcosine is shown in Figure 4.

Primary product assignment was confirmed by adding authentic sarcosine to the photodegraded reaction mixture. Peaks in the HPLC trace recorded from this degraded sample/authentic sarcosine mix were found to be coincident with peaks in the HPLC trace recorded from the degraded reaction mixture alone (compare sample row 5 with sample row 4 in Table 2).

At longer times, both the concentration of secondary amine as determined by the $\mathrm{N}$-nitroso method and the area of the peak at $R_{t}=1.523$ minutes, associated with the secondary amine sarcosine, were seen to decrease with illumination time. The latter was accompanied by the concomitant formation of a second product peak at $R_{t}=$ 1.56 minutes, in the vicinity of but not coincident with the sarcosine peak in the HPLC trace. Again, by addition of 
TABLE 2: Table showing HPLC peaks retention times, $R_{t}$, for glyphosate, sarcosine, glycine (sample rows $1-3$, resp.), irradiated mixtures of glyphosate at pH 3 and pH 11 (sample rows 4 and 6, resp.), and irradiated mixtures of glyphosate at pH 3 and pH 11 with authentic samples of sarcosine and glycine (sample rows 5 and 7, resp.). Peaks associated with glyphosate, sarcosine, and glycine are shown as bold, underlined, and double underlined text, respectively.

\begin{tabular}{|c|c|}
\hline Sample & HPLC peak retention time $\left(R_{t}\right) /$ minutes \\
\hline 1. Glyphosate (from Figure 3) & $0.941(\min ), 1.184(\mathrm{~s})$ \\
\hline 2. Sarcosine (from Figure 4) & $\underline{1.105}(\mathrm{w}), \underline{1.531}(\mathrm{~s})$ \\
\hline 3. Glycine (from Figure 5) & $\underline{\underline{0.834}}(\mathrm{w}), \underline{\underline{1.558}}(\mathrm{~s})$ \\
\hline 4. Glyphosate, 90 min Irradiation, $\mathrm{pH} 3$ & $0.948(\min ), 1.061(\min ), 1.13(\mathrm{~s}), 1.599(\min ), 1.651(\mathrm{~s})$ \\
\hline 5. Glyphosate (90 min irradiation, $\mathrm{pH} 3)+$ authentic Sarcocine & $0.948(\min ), 1.039(\min ), \underline{1.117}(\mathrm{~s}), \underline{1.523}(\mathrm{~min}), 1.651(\mathrm{~s})$, \\
\hline 6. Glyphosate (60 min irradiation, $\mathrm{pH} 11)$ & $1.161(\mathrm{~s}), 1.548(\mathrm{~min}), 1.662(\mathrm{~min})$ \\
\hline 7. Glyphosate (60 min irradiation, $\mathrm{pH} 11)+$ authentic Glycine & $1.108(\mathrm{~s}), \underline{\underline{1.543}}(\mathrm{~min}), 1.665(\mathrm{~min})$ \\
\hline
\end{tabular}

s-strong, m-medium, w-weak.
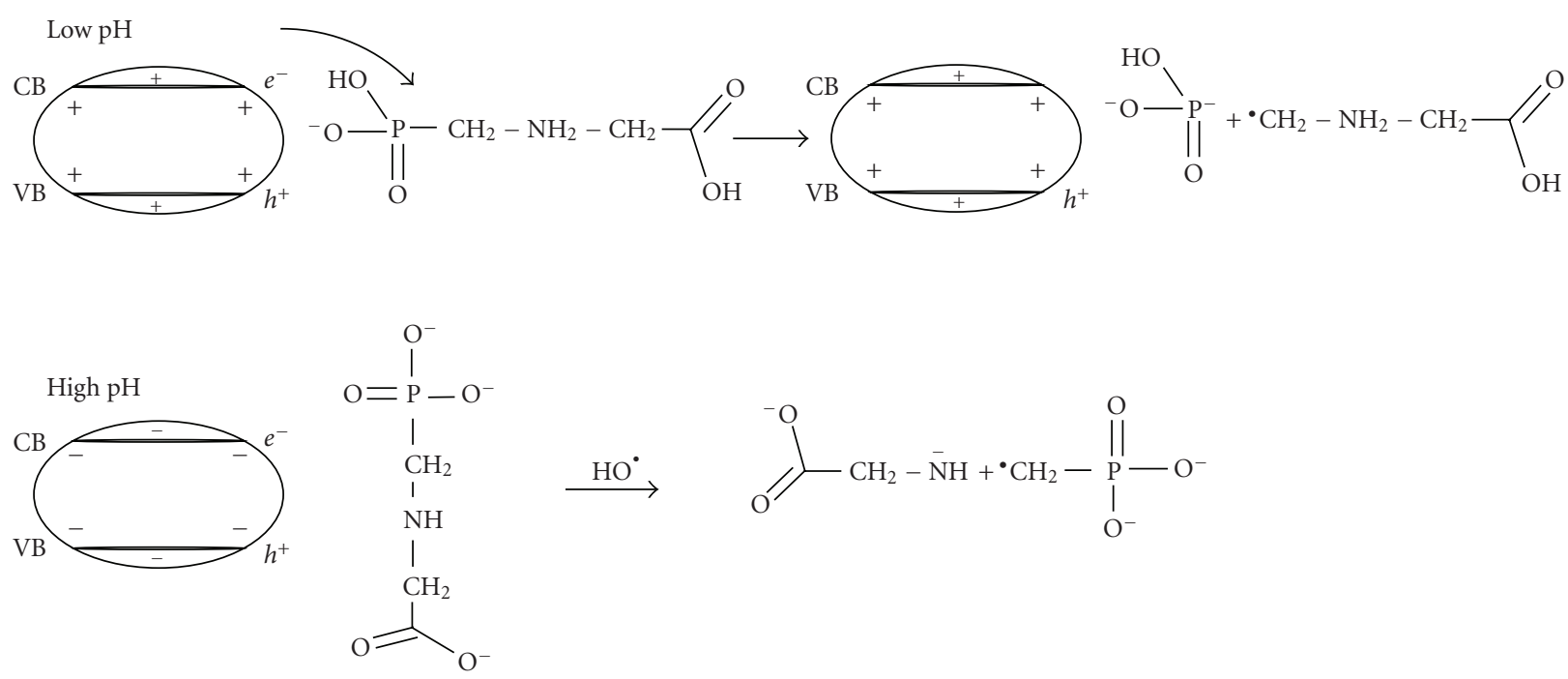

FIGURE 6: The interaction of glyphosate with the surface of $\mathrm{TiO}_{2}$ in dark and the subsequent interaction of photogenerated electrons and hydroxyl radicals with glyphosate upon illumination of the $\mathrm{TiO}_{2}$ with ultraband gap irradiation.

authentic material to photodegraded reaction mixtures, this second product was identified as glycine-2-aminoethanoic acid. The HPLC trace of authentic glycine is shown in Figure 5.

HPLC analysis of photodegraded reaction mixtures at $\mathrm{pH}$ 11 also indicates the formation of product $\left(R_{t}=1.548\right.$ and 1.662 minutes) in the vicinity of but not coincident with the sarcosine peak in the HPLC trace. No sarcosine peak was observed at any irradiation time at this $\mathrm{pH}$. Following the methodology employed at $\mathrm{pH} 3, \mathrm{HPLC}$ analyses of the photodegraded reaction mixture and samples of authentic materials shows that the primary reaction product is glycine (compare sample row 7 with sample row 6 in Table 2 and note coincidence of peaks at $R_{t}=1.548$ minutes). This is most likely derived from $\mathrm{C}-\mathrm{N}$ bond cleavage in nonadsorbed glyphosate (Figure 6).

The N-nitroso-based secondary amine analysis of Figure 2 indicates that at low $\mathrm{pH}$, secondary amine is retained but glyphosate is lost due to loss of phosphate group and appearance of a peak in the carboxylic acid region of the HPLC trace. In conjunction with the product identification and the fact that adsorption occurs at low $\mathrm{pH}$, the results suggest that at low $\mathrm{pH}$ the photocatalytic reaction is most likely initiated by from-particle electron transfer. In contrast, under alkaline $\mathrm{pH}$ where little adsorption is seen to occur (Figure 1) solution-phase hydroxyl radical attack plays an important role, said hydroxide radicals having been generated in the reaction medium by photogenerated holes.

Figure 6 provides a schematic summary of these processes, wherein it is assumed that, at low $\mathrm{pH}$, the photogenerated electron on irradiated $\mathrm{TiO}_{2}$ attacks through -phosphate-adsorbed-glyphosate leading to the formation of carbon centered radical which then reacts to form nonadsorbed sarcosine. Readsorption of sarcosine onto the positively charged $\mathrm{TiO}_{2}$ surface is then inhibited by the anticipated net positive charge on the molecule, arising from the protonation of the secondary amino nitrogen at this $\mathrm{pH}$. At high $\mathrm{pH}$, photoelectrochemically generated hydroxyl radicals attack nonadsorbed glyphosate, causing $\mathrm{C}-\mathrm{N}$ bond fracture and ultimately forming glycine. It is pertinent to 


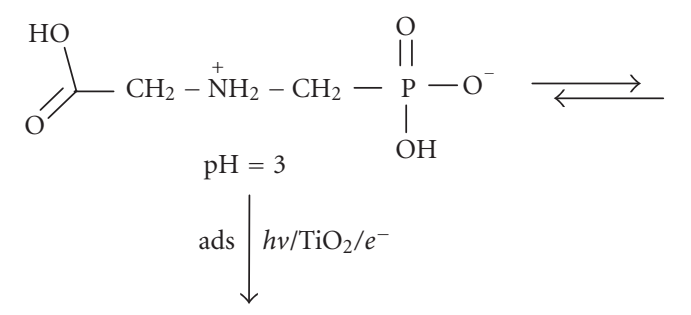<smiles>O=C(O)CNCP(=O)([O-])[O-]</smiles><smiles>CNCC(=O)O</smiles><smiles>COC(=O)C[NH3+]</smiles>

$\mathrm{HOOC}-\mathrm{CH}_{2}-\mathrm{NH}_{2}+\mathrm{CH}_{3}-\mathrm{PO}_{3} \mathrm{H}_{2}$

rcosine

Glycine<smiles>C=CCO[PbH2]</smiles>

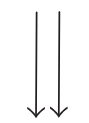

$\mathrm{CH}_{3} \mathrm{COOH}+\mathrm{CH}_{3} \mathrm{NH}_{2}$

Scheme 2: Scheme showing the probable route for the degradation of glyphosate on irradiated $\mathrm{TiO}_{2}$ at low and high $\mathrm{pH}$.

mention here that photocatalysed degradation of glycine has a well-known mechanism and has been reported earlier [34]. Returning to $\mathrm{pH} \mathrm{3,} \mathrm{it} \mathrm{can} \mathrm{now} \mathrm{be} \mathrm{seen} \mathrm{that} \mathrm{sarcosine}$ which is not adsorbed at the $\mathrm{TiO}_{2}$ surface due to the loss of the phosphate group is then susceptible to similar solutionphase $\mathrm{OH}$ radical attack as nonadsorbed glyphosate at $\mathrm{pH}$ 11, so generating the same product, glycine. A mechanism consistent with these observations is shown in Scheme 2.

\section{CONCLUSIONS}

The pesticide derivative glyphosate has been found to degrade efficiently under alkaline conditions. Under acid conditions, it exhibits a strong, primarily coulombically driven dark adsorption onto the surface of the $\mathrm{TiO}_{2}$ photocatalyst. Again, under acid conditions, the compound has been found to undergo efficiently photocatalytically promoted $\mathrm{P}-\mathrm{C}$ bond cleavage leading to the formation of sarcosine and glycine like the main intermediate products. A probable degradation route involving a direct interfacial electron transfer reaction at low $\mathrm{pH}$ and hydroxyl radical /superoxide radical anion-mediated solution-phase oxidation at high $\mathrm{pH}$ on irradiated semiconductor particles has been proposed.

\section{ACKNOWLEDGMENTS}

Financial support from European Commission (Contract no. Mesocat 514289) and the award of a Marie Curie Incoming International Fellowship to Mohammad Muneer. are gratefully acknowledged.

\section{REFERENCES}

[1] Z. Z. Cohen, C. Eiden, and M. N. Lober, "Monitoring ground water for pesticides," in Evaluation of Pesticides in Ground Water, W. Y. Gernar, Ed., ACS Symposium Series 315, pp. 170196, Washington, DC, USA, American Chemical Society, 1986.

[2] L. Muszkat, D. Raucher, M. Mogaritz, and D. Ronen, "Groundwater contamination by organic pollutants," in Groundwater Contamination and Control, pp. 257-272, Marcel Dekker, New York, NY, USA, 1994.

[3] J. A. Graham, "Monitoring groundwater and well water for crop protection chemicals," Analytical Chemistry, vol. 63, no. 11, pp. 631-622, 1991.

[4] R. M. Dowd, M. P. Anderson, and M. L. Johnson, "Ground water monitoring and geophysical method," in Proceedings of the 2nd National Outdoor Action Conference on Aquifer Restoration, Ground Water Monitoring and Geophysical Methods, pp. 1365-1379, National Water Well Association, Dublin, Ohio, USA, May 1988.

[5] J. Mönig, D. W. Bahnemann, and K.-D. Asmus, "One electron reduction of $\mathrm{CCl}_{4}$ in oxygenated aqueous solutions: a $\mathrm{CCl}_{3} \mathrm{O}_{2}^{\circ}$ free radical mediated formation of $\mathrm{Cl}^{-}$and $\mathrm{CO}_{2}$," ChemicoBiological Interactions, vol. 47, no. 1, pp. 15-27, 1983.

[6] D. M. Blake, "Bibliography of work on the photocatalytic removal of hazardous compounds from water and air," Tech. Rep. NREL/TP-510-31319, National Renewal Energy Laboratory, Cole Boulevard Golden, Colo, USA, 2001.

[7] M. Abu Tariq, M. Faisal, M. Muneer, and D. W. Bahnemann, "Photochemical reactions of a few selected pesticide derivatives and other priority organic pollutants in aqueous suspensions of titanium dioxide," Journal of Molecular Catalysis A, vol. 265, no. 1-2, pp. 231-236, 2007.

[8] D. W. Bahnemann, M. Muneer, and M. M. Haque, "Titanium dioxide-mediated photocatalysed degradation of few selected 
organic pollutants in aqueous suspensions," Catalysis Today, vol. 124, no. 3-4, pp. 133-148, 2007.

[9] N. N. Rao and S. Dube, "Photocatalytic degradation of mixed surfactants and some commercial soap/detergent products using suspended $\mathrm{TiO}_{2}$ catalysts," Journal of Molecular Catalysis A, vol. 104, no. 3, pp. L197-L199, 1996.

[10] I.-W. Huang, C.-S. Hong, and B. Bush, "Photocatalytic degradation of $\mathrm{PCBs}$ in $\mathrm{TiO}_{2}$ aqueous suspensions," Chemosphere, vol. 32, no. 9, pp. 1869-1881, 1996.

[11] M. M. Haque, M. Muneer, and D. W. Bahnemann, "Semiconductor-mediated photocatalyzed degradation of a herbicide derivative, chlorotoluron, in aqueous suspensions," Environmental Science \& Technology, vol. 40, no. 15, pp. 47664770, 2006.

[12] J. Blanco-Galvez, P. Fernández-Ibáñez, and S. MalatoRodríguez, "Solar photocatalytic detoxification and disinfection of water: recent overview," Journal of Solar Energy Engineering, vol. 129, no. 1, pp. 4-15, 2007.

[13] K. Tanaka, S. M. Robledo, T. Hisanaga, R. Ali, Z. Ramli, and W. A. Bakar, "Photocatalytic degradation of 3,4-xylyl $N$ methylcarbamate (MPMC) and other carbamate pesticides in aqueous $\mathrm{TiO}_{2}$ suspensions," Journal of Molecular Catalysis A, vol. 144, no. 3, pp. 425-430, 1999.

[14] J. Lobedank, E. Bellmann, and J. Bendig, "Sensitized photocatalytic oxidation of herbicides using natural sunlight," Journal of Photochemistry and Photobiology A, vol. 108, no. 1, pp. 8993, 1997.

[15] K. Vinodgopal, D. E. Wynkoop, and P. V. Kamat, "Environmental photochemistry on semiconductor surfaces: photosensitized degradation of a textile azo dye, acid orange 7 , on $\mathrm{TiO}_{2}$ particles using visible light," Environmental Science \& Technology, vol. 30, no. 5, pp. 1660-1666, 1996.

[16] I. Liu, L. A. Lawton, B. Cornish, and P. K. I. Robertson, "Mechanistic and toxicity studies of the photocatalytic oxidation of microcystin-LR," Journal of Photochemistry and Photobiology A, vol. 148, no. 1-3, pp. 349-354, 2002.

[17] R. Borello, C. Minero, E. Pramauro, E. Pelizzetti, N. Serpone, and H. Hidaka, "Photocatalytic degradation of DDT mediated in aqueous semiconductor slurries by simulated sunlight," Environmental Toxicology and Chemistry, vol. 8, no. 11, pp. 997-1002, 1989.

[18] J.-M. Herrmann, "Heterogeneous photocatalysis: fundamentals and applications to the removal of various types of aqueous pollutants," Catalysis Today, vol. 53, no. 1, pp. 115129, 1999.

[19] C. S. Turchi and D. F. Ollis, "Photocatalytic degradation of organic water contaminants: mechanisms involving hydroxyl radical attack," Journal of Catalysis, vol. 122, no. 1, pp. 178192, 1990.

[20] R. W. Matthews and S. R. McEvoy, "Photocatalytic degradation of phenol in the presence of near-UV illuminated titanium dioxide," Journal of Photochemistry and Photobiology A, vol. 64, no. 2, pp. 231-246, 1992.

[21] J. E. Franz, M. K. Mao, and J. A. Sikorski, Glyphosate: A Unique Global Herbicide, chapter 4, American Chemical Society, Washington, DC, USA, 1997.

[22] P. Sprankle, W. F. Meggitt, and D. Penner, "Rapid inactivation of glyphosate in the soil," Weed Science, vol. 23, no. 3, pp. 224228, 1975.

[23] P. Sprankle, W. F. Meggitt, and D. Penner, "Adsorption, mobility and microbial degradation of glyphosate in the soil," Weed Science, vol. 23, no. 3, pp. 229-234, 1975.

[24] M. L. Rueppel, B. B. Brightwell, J. Schaefer, and J. T. Marvel, "Metabolism and degradation of glyphosate in soil and water,"
Journal of Agricultural Food Chemisry, vol. 25, no. 3, pp. 517$528,1977$.

[25] R. L. Glass, "Adsorption of glyphosate by soils and clay minerals," Journal of Agricultural Food Chemistry, vol. 35, no. 4, pp. 497-500, 1987.

[26] D. N. Roy, S. K. Konar, S. Banerjee, D. A. Charles, D. G. Thompson, and R. Prasad, "Persistence, movement, and degradation of glyphosate in selected Canadian boreal forest soils," Journal of Agricultural Food Chemistry, vol. 37, no. 2, pp. 437-440, 1989.

[27] N. S. Normura and H. W. Hilton, "The adsorption and degradation of glyphosate in five Hawaiian sugarcane soils," Weed Research, vol. 17, no. 2, pp. 113-121, 1977.

[28] J. Malik, G. Barry, and G. kishore, "The herbicide glyphosate," BioFactors, vol. 2, no. 1, pp. 17-25, 1989.

[29] S. M. Carlisle and J. T. Trevorrs, "Glyphosate in the environment," Water, Air, \& Soil Pollution, vol. 39, no. 3-4, pp. 409420, 1988.

[30] K. Lund-Høie and H. O. Friestad, "Photodegradation of the herbicide glyphosate in water," Bulletin of Environmental Contamination and Toxicology, vol. 36, no. 1, pp. 723-729, 1986.

[31] C. Shifu and L. Yunzhang, "Study on the photocatalytic degradation of glyphosate by $\mathrm{TiO}_{2}$ photocatalyst," Chemosphere, vol. 67, no. 5, pp. 1010-1017, 2007.

[32] "Highly Dispersed Metallic Oxides Produced by the AEROSIL ${ }^{\circledR}$ Process," Degussa Technical Bulletin, no. 56, p. 8, 1984 .

[33] R. I. Bickley, T. Gonzalez-Carreno, J. S. Lees, L. Palmisano, and R. J. D. Tilley, "A structural investigation of titanium dioxide photocatalysts," Journal of Solid Sate Chemistry, vol. 92, no. 1, pp. 178-190, 1997.

[34] S. Horikoshi, N. Serpone, J. Zhao, and H. Hidako, "Towards a better understanding of the initial steps in the photocatalyzed mineralization of amino acids at the titania/water interface. An experimental and theoretical examination of L-alanine, L-serine and L-phenylalanine," Journal of Photochemistry and Photobiology A, vol. 118, no. 2, pp. 123-129, 1998. 


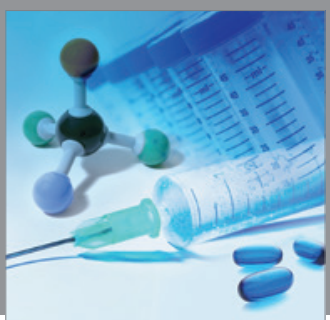

International Journal of

Medicinal Chemistry

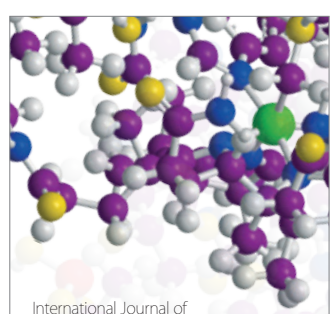

Carbohydrate Chemistry

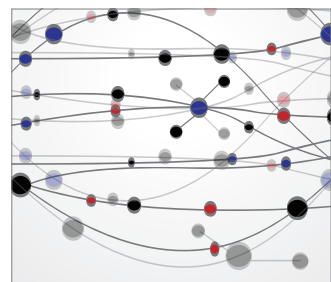

The Scientific World Journal
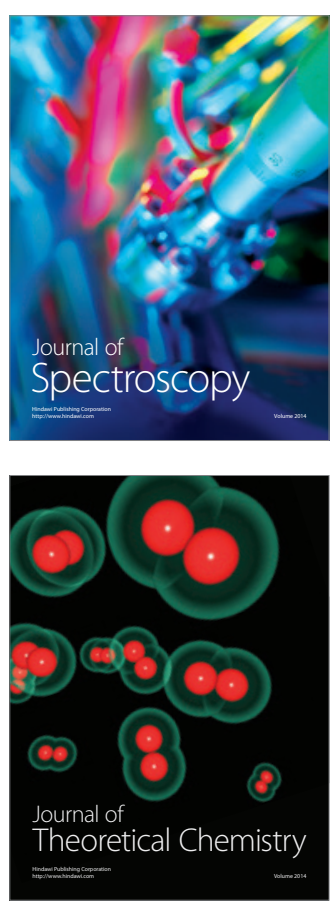
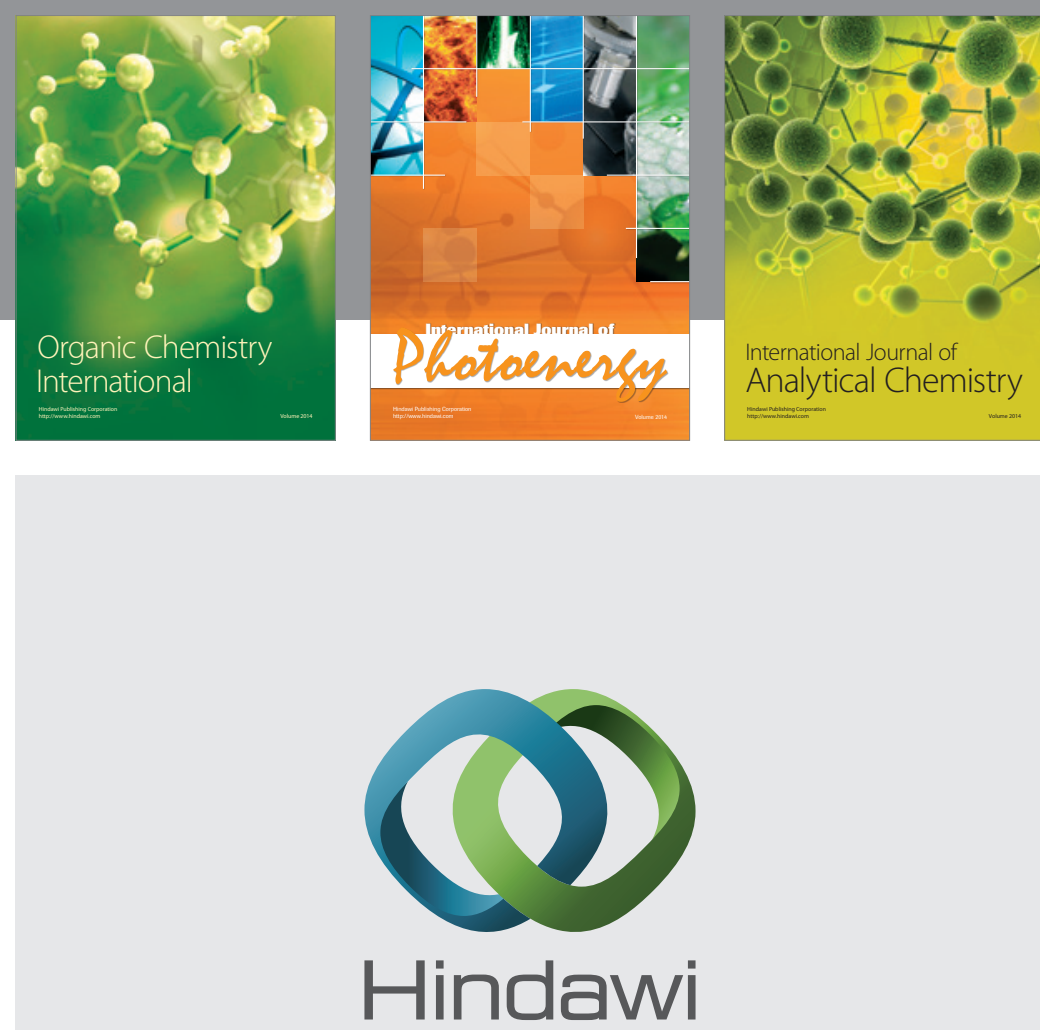

Submit your manuscripts at

http://www.hindawi.com
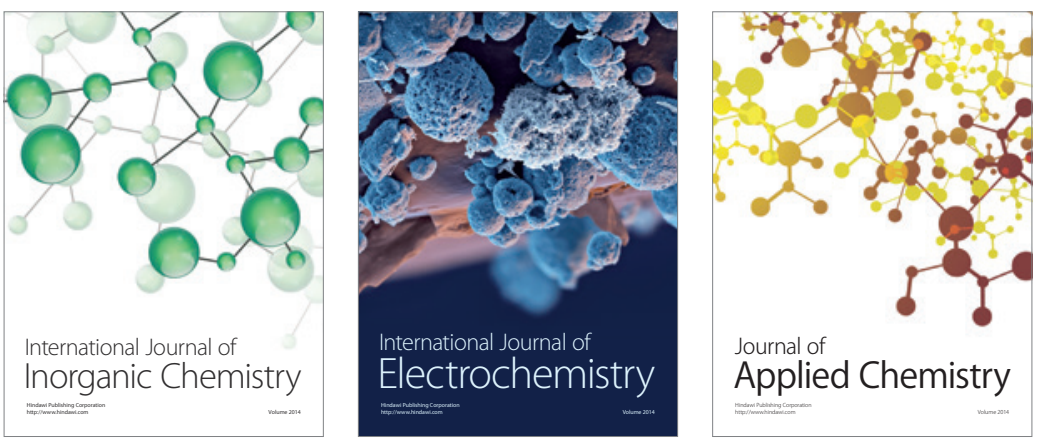

Journal of

Applied Chemistry
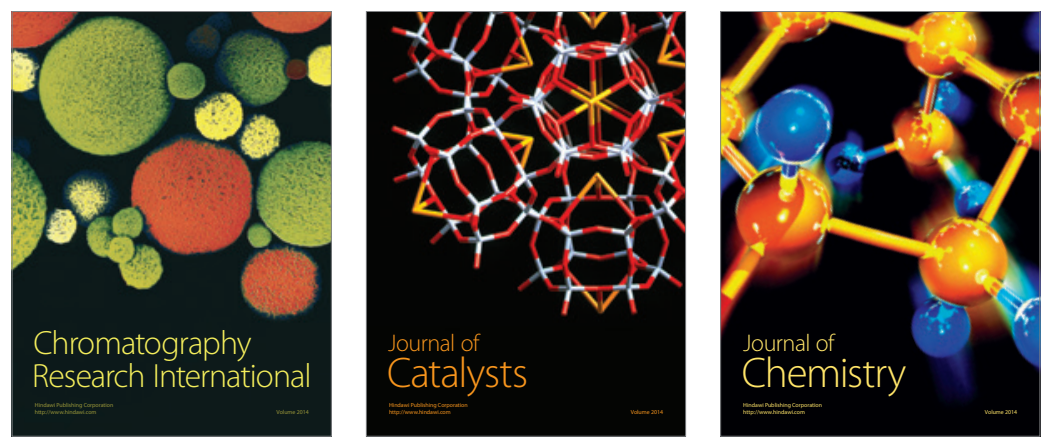
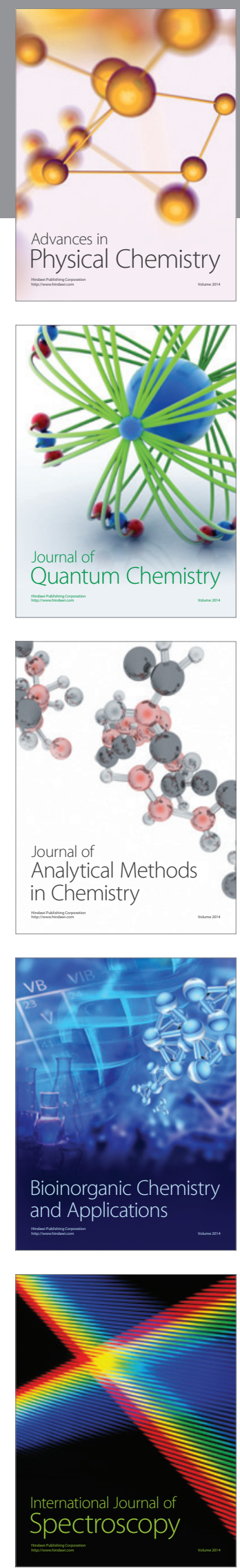